\title{
Compilation of tRNA sequences
}

D.H.Gauss, F.Grüter and M.Sprinzl

Abteilung Chemie, Max-Planck-Institut für experimentelle Medizin, Hermann-Rein-Str. 3, D-3400 Göttingen, GFR

Received 19 December 1978

\section{INTRODUCTION}

This compilation presents in a small space the tRNA sequences so far published in order to enable rapid orientation and comparison. The numbering of tRNA Phe from yeast is used as has been done earlier (1) but following the rules proposed by the participants of the Cold Spring Harbor Meeting on tRNA 1978 (2) (Fig. 1). This numbering allows comparisons with the three dimensional structure of tRNAPhe, the only structure known from x-ray analysis. The secondary structure of tRNAs is indicated by specific underlining. In the primary structure a nucleoside followed by a nucleoside in brackets or a modification in brackets denotes that both types of nucleosides can occupy this position. Part of a sequence in brackets designates a piece of sequence not unambiguously analyzed. Rare nucleosides are named according to the IUPACIUB rules (for some more complicated rare nucleosides and their identification see Table 1); those with lengthy names are given with the prefix $x$ and specified in the footnotes. Footnotes are numbered according to the coordinates of the corresponding nucleoside and are indicated in the sequence by an asterisk. The references are restricted to the citation of the latest publication in those cases where several papers deal with one sequence. For additional information the reader is referred either to the original literature or to other tRNA sequence compilations (3-7). Mutant tRNAs are dealt with in a separate compilation prepared by $\mathrm{J}$. Celis (see below). The compilers would welcome any information by the readers regarding missing material or erroneous presentation. On the basis of this numbering system computer printed compilations of tRNA sequences in a linear form and in cloverleaf form are in preparation.

1. M. Sprinzl, F. Grüter, D.H. Gauss (1978) Nucleic Acids Research $\underline{5}, r 15-r 27$.

2. This rules are given with the compilation of tRNA sequences by D.H. Gauss, F. Grüter, M. Sprinzl in J. Abelson, P.R. Schimmel, D. Söll (Ed.) (1979) Cold Spring Harbor Symposia on Quantitative Biology, in press.

3. M.A. Sodd in G.D. Fasman (Ed.), CRC Handbook of Biochemistry and Molecular Biology, 3rd Edition, Nucleic Acids Vol. II, p. 423-456, The Chemical Rubber Company, Cleveland, 1976.

4. G. Dirheimer, J.P. Ebel, J. Bonnet, J. Gangloff, G. Keith, B. Krebs, B. Kuntzel, A. Roy, J. Weissenbach, C. Werner (1972) Biochimie 54, 127-144.

5. N.A. Sodd, B.P. Doctor (1974) Methods Enzymol. 29, 741-756. 
6. B.G. Barrell, B.F.C. Clark, Handbook of Nucleic Acid Sequences, JoynsonBruvvers Ltd. Oxford, 1974.

7. J. Barciszewski, A.J. Rafalski, Atlas of Transfer Ribonucleic Acids and Modified Nucleosides, Poznan; 1978, in press.

Table 1: Names of Some Rare Nucleosides and Citations Regarding their Identification

compare: M.Y. Feldman (1978) Progr.Biophys.Mol.Biol. 32, 83-102;

J.P. Goddard (1978) Progr.Biophys.Mol.Biol. $\overline{32}, 233-308$;

J.A. McCloskey, S. Nishimura (1977) Accounts Chem.Res. 10, 403-410.

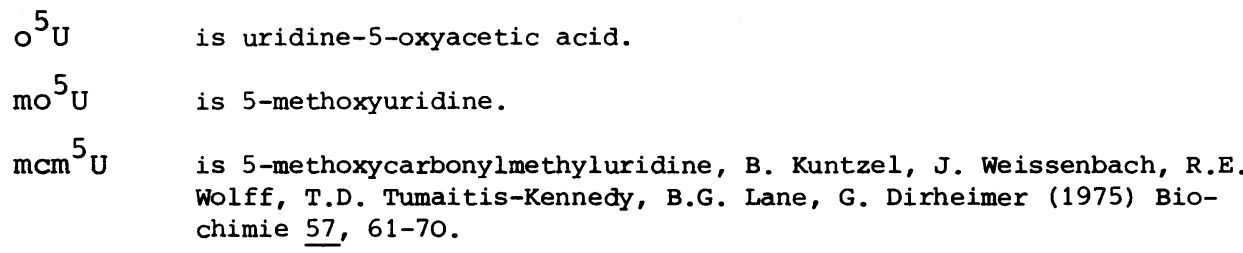

$\mathrm{mcm}^{5} \mathrm{~s}^{2} \mathrm{U}$ is 5-methoxycarbonylmethyl-2-thiouridine.

$\operatorname{mam}^{5} \mathrm{~s}^{2} \mathrm{U}$ is 5-N-methylaminomethyl-2-thiouridine.

$i^{6} \mathrm{~A} \quad$ is $\mathrm{N}-6-\left(\Delta^{2}-i\right.$ sopen teny 1$)$ adenosine.

$\mathrm{ms}^{2} \mathrm{i}^{6} \mathrm{~A}$ is $\mathrm{N}-6-\left(\Delta^{2}\right.$-isopentenyl) 2-methylthioadenosine, F. Harada, H.J. Gross, F. Kimura, S.H. Chang, S. Nishimura, U.L. RajBhandary (1968) Biochem.Biophys.Res.Commun 33, 299-306; Y. Yamada, S. Nishimura, H. Ishikura (1971) Biochim. Biophys.Acta 247, 170-174.

$t^{6} \mathrm{~A}$ is $\mathrm{N}-[9-(B-D-r i b o f u r a n o s y 1)$ purin-6-ylcarbamoyl] threonine.

$m t^{6} \mathrm{~A}$ is $\mathrm{N}-[9-(B-D-r i b o f u r a n o s y l)$ purin-6-yl-N-methylcarbamoy 1$]$ threon ine.

$Q_{34}$ is 7-(4,5-cisdihydroxy-1-cyclopenten-3-ylaminome thyl)-7-deazaguanosine, H. Casai, Z. Ohashi, F. Harada, S. Nishimura, N.J. Oppenheimer, P.F. Crain, J.G. Liehr, D.L. von Minden, J.A. McCloskey (1975) Biochem. $14,4198-4208$.

$\mathrm{X}$ is 3-N-(3-amino-3-carboxypropyl) uridine, S. Nishimura, Y. Taya, Y. Kuchino, Z. Ohashi (1974) Biochem.Biophys.Res.Commun. 57, 702-708; Z. Ohashi, M. Maeda, J.A. McCloskey, S. Nishimura (1974) Biochem. 13, 2620-2625; S. Friedman, H.J. Li, K. Nakanishi, G. van Lear (197 $\overline{4)}$ Biochem. 13, 2932-2937.

yW is wybutosine, K. Nakanishi, N. Furutachi, M. Funamizu, D. Grunberger, I.B. Weinstein (1970) J.Amer.Chem.Soc. 92, 7617-7619.

$\mathrm{O}_{2} \mathrm{YW}$ is wybutoxosine, S.H. Blobstein, D. Grunberger, I.B. Weinstein, K. Nakanishi (1973) Biochem. 12, 188-193; A.M. Feinberg, K. Nakanishi, J. Barciszewski, A.J. Rafalski, H. Augustyniak, M. Wiewiorowski (1974) J.Amer.Chem.Soc. 96, 7797-7800.

$\mathrm{N}$ is an unknown nucleoside. 


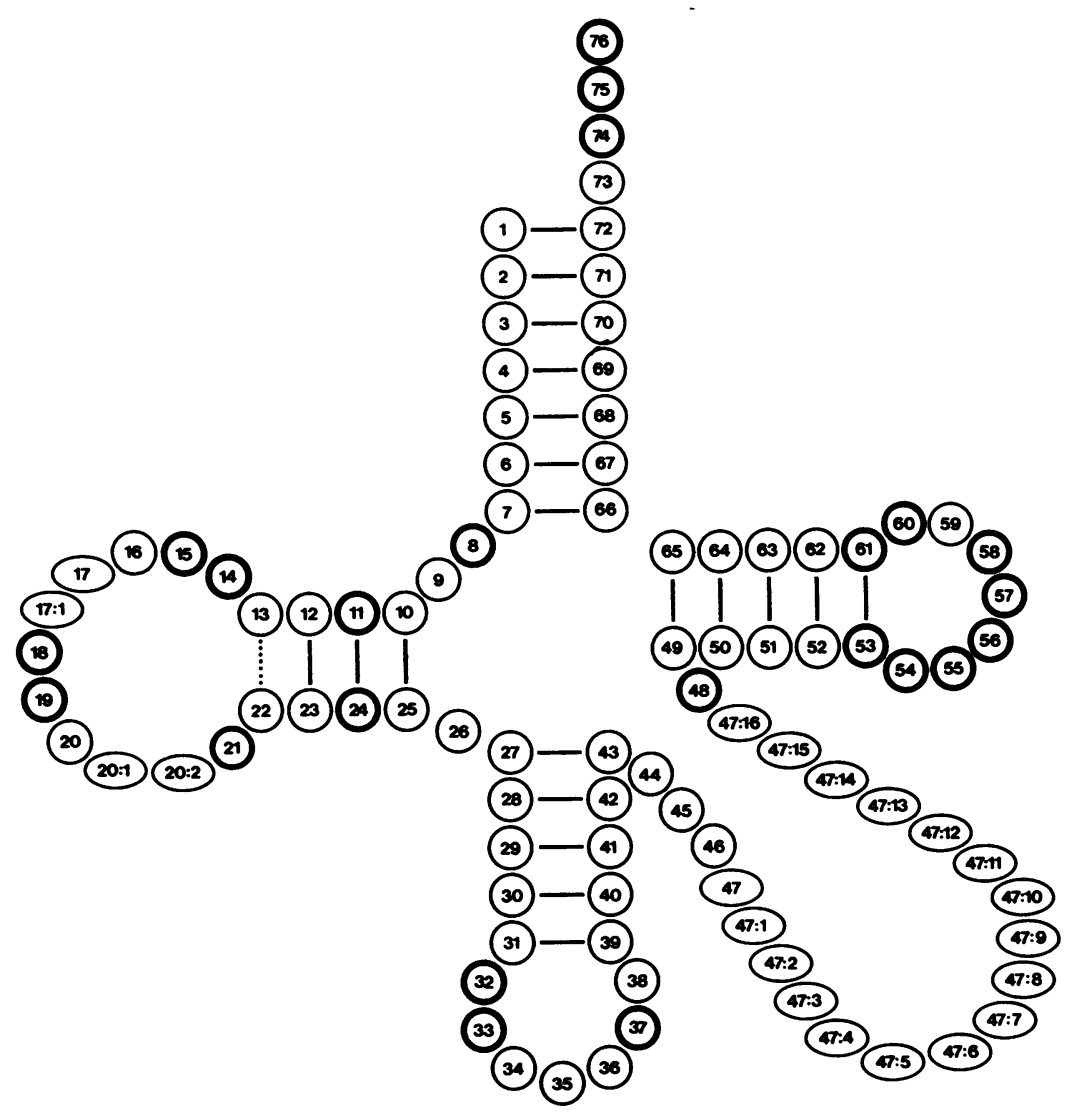

Figure 1: Numbering system of nucleotides in tRNAs according to the numbering of phenylalanine tRNA from yeast. Circles represent nucleotides which are always present; among these, the thick-edged circles denote invariant or semiinvariant nucleotides. Ovals represent nucleotides which are not present in each sequence: these are the nucleotides before the two constant GMP residues (18, 19) in the D loop, the nucleotides after these GMP residues, and the nucleotides in the variable loop which may be up to 17 nucleotides.

A nucleotide to be added at a given site is indicated by the number of the preceding nucleotide followed by a colon and a further number. Thus, e.g. 20:1 and 20:2 mean the first and second nucleotide after position 20. The absence of a nucleotide is indicated by the absence of a number, e.g. if no residue is found in position 17, the sequence then reads C16-G18. The numbering for the D loop, when one, two or three nucleotides are present each between 15 and 18 or between 19 and 21 , is then 16 and 16,17 and $16,17,17: 1$ or 20 and 20, $20: 1$ and 20, 20:1, 20:2, respectively. When the variable loop is five-membered the numbering is as in yeast phenylalanine tRNA $44,45,46,47,48.47$ is eliminated as the three dimensional structure of yeast phenylalanine tRNA suggests when the variable loop is four-membered. For large variable loops, numbers are added onto 47 , e.g. for thirteen nucleotides $44,45,46,47,47: 1,47: 2,47: 3$, $47: 4,47: 5,47: 6,47: 7,47: 8,48$. 


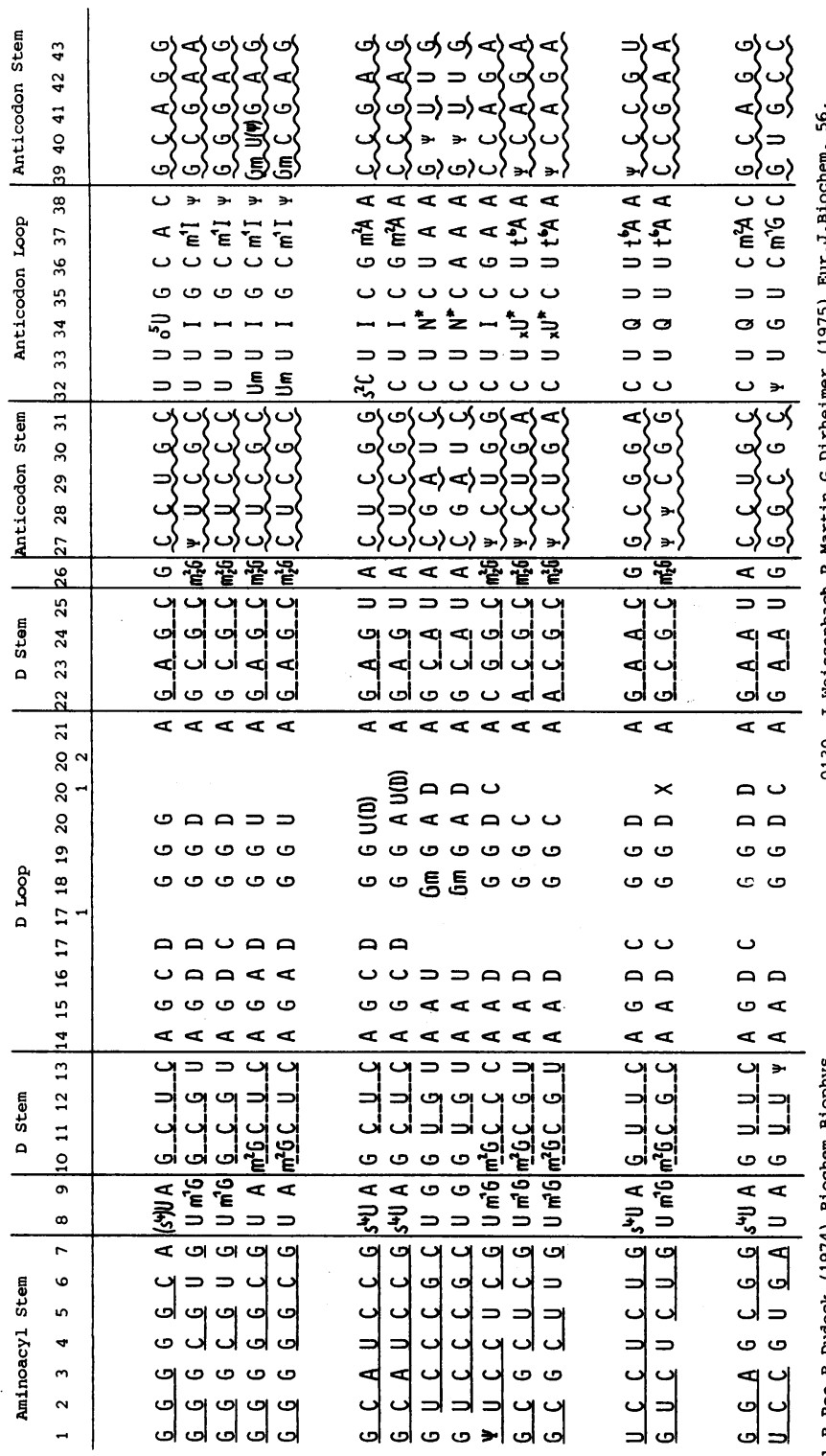

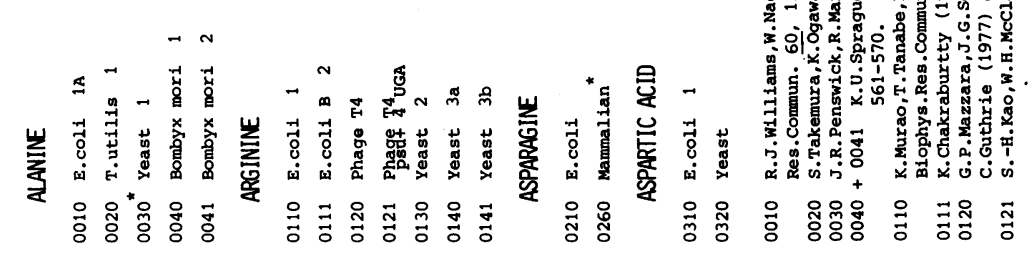




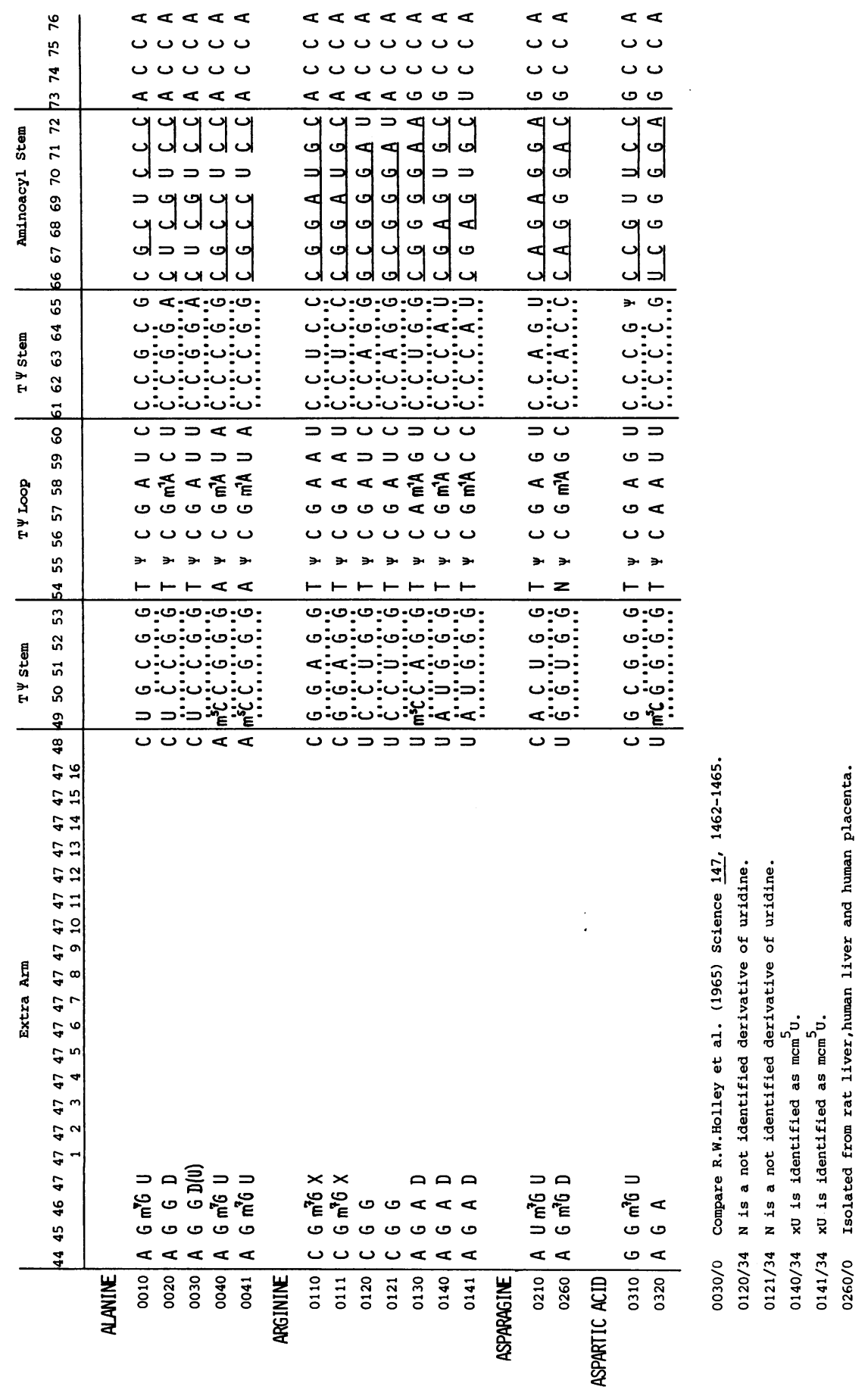




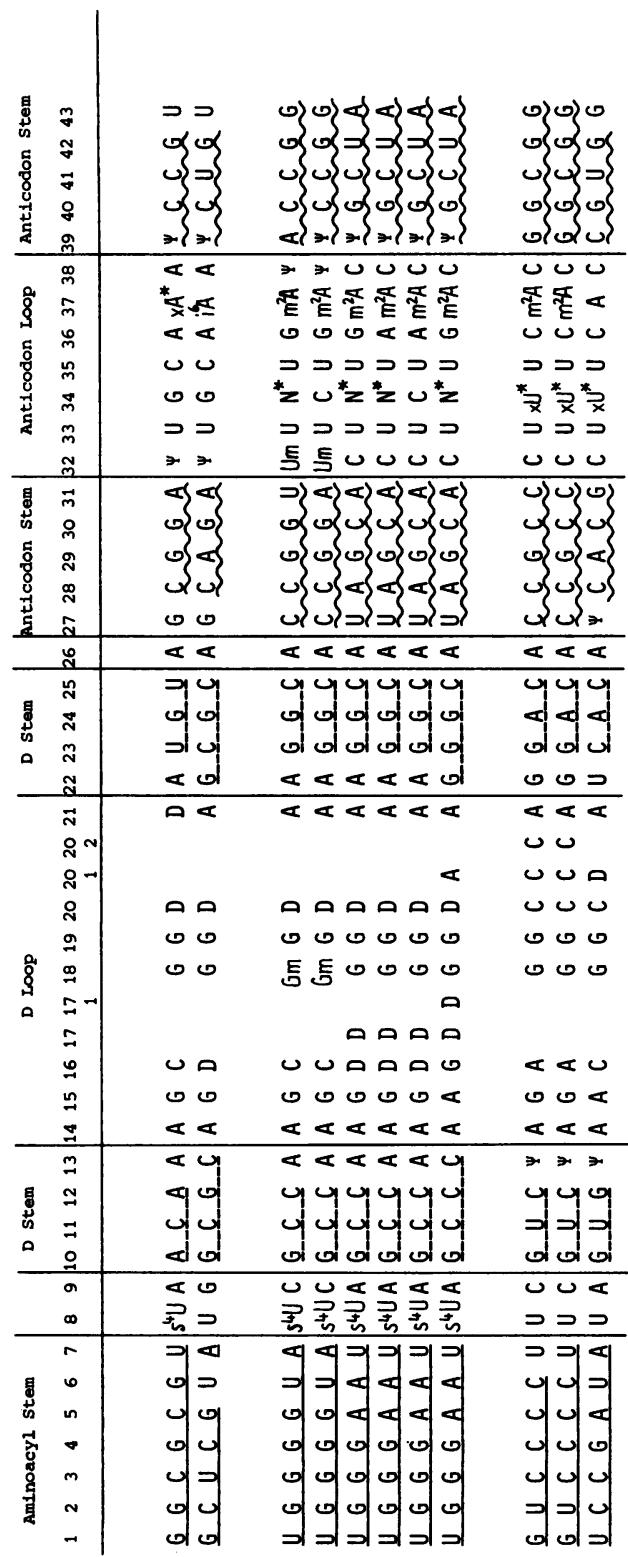

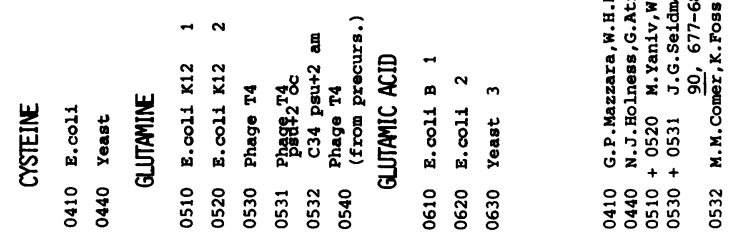




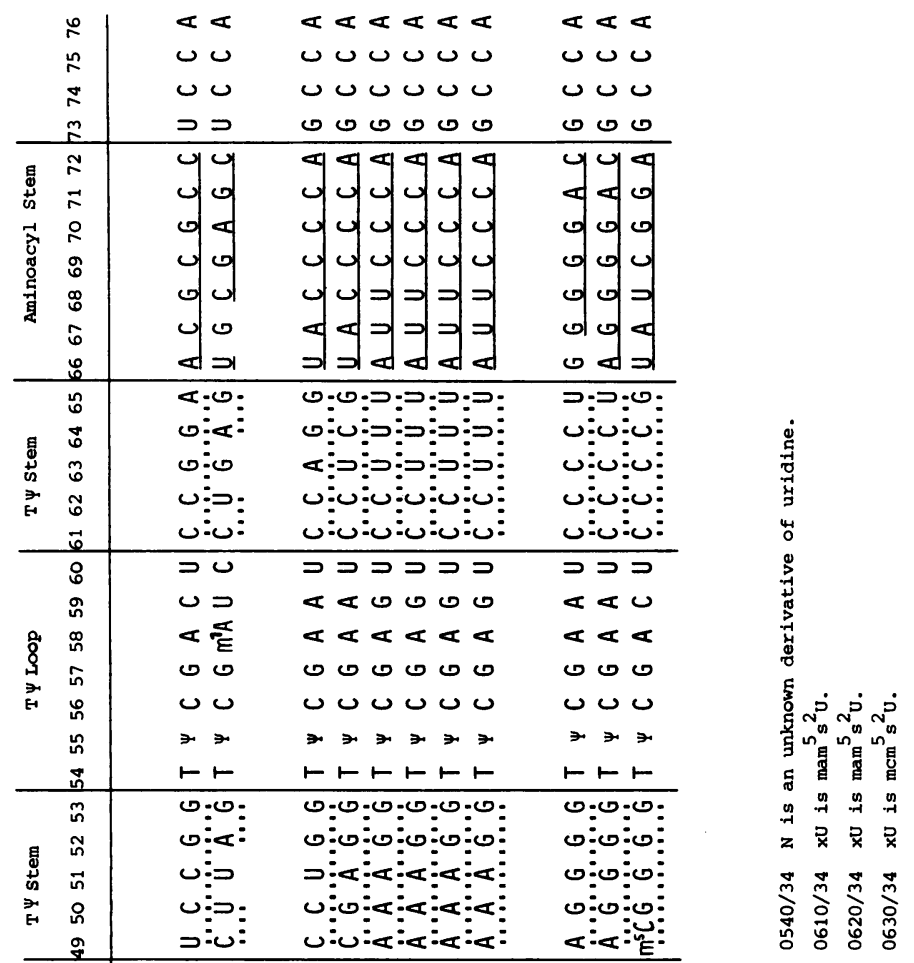

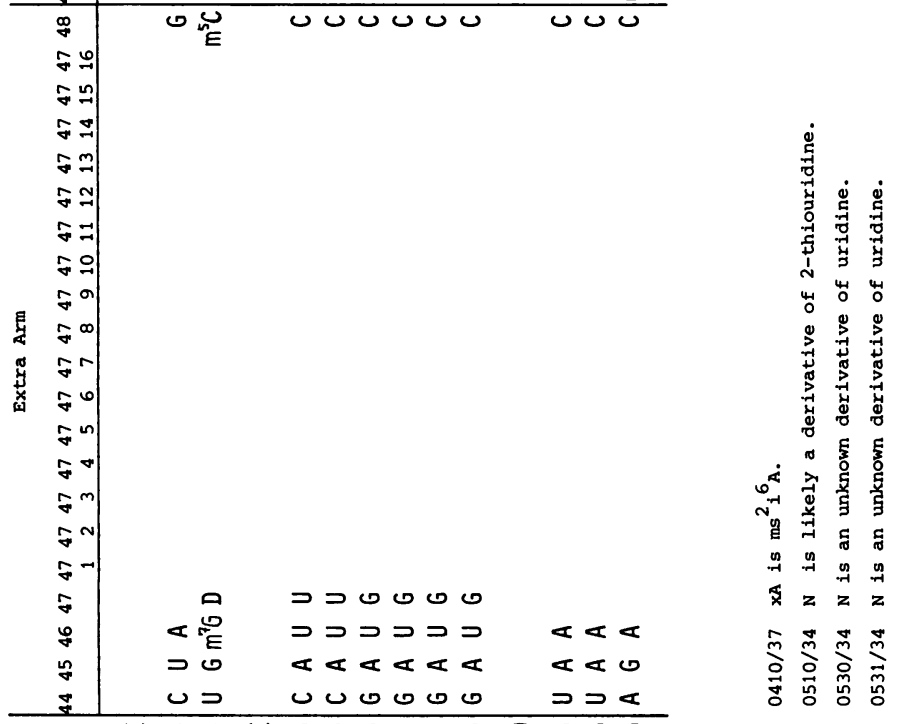




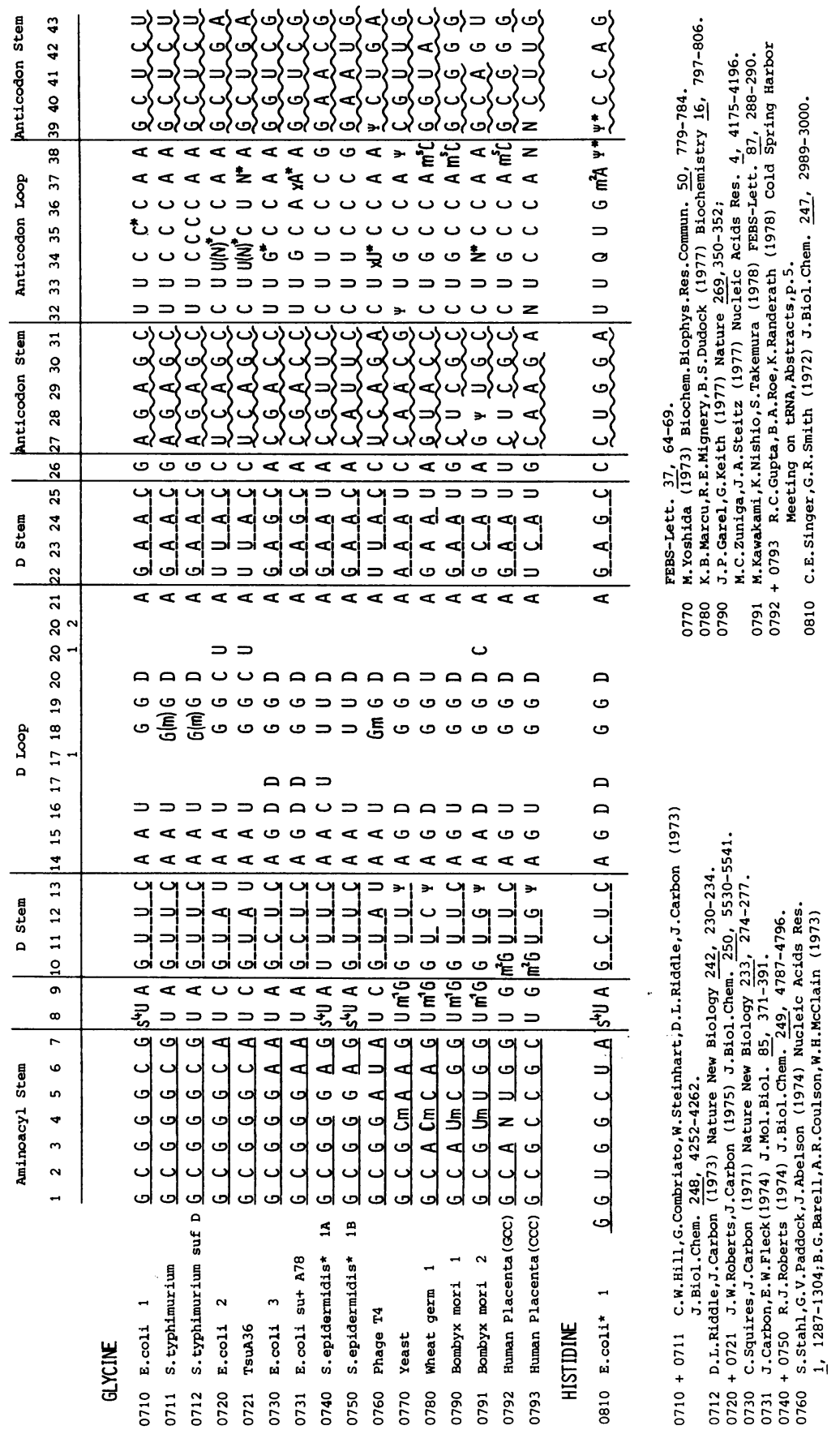




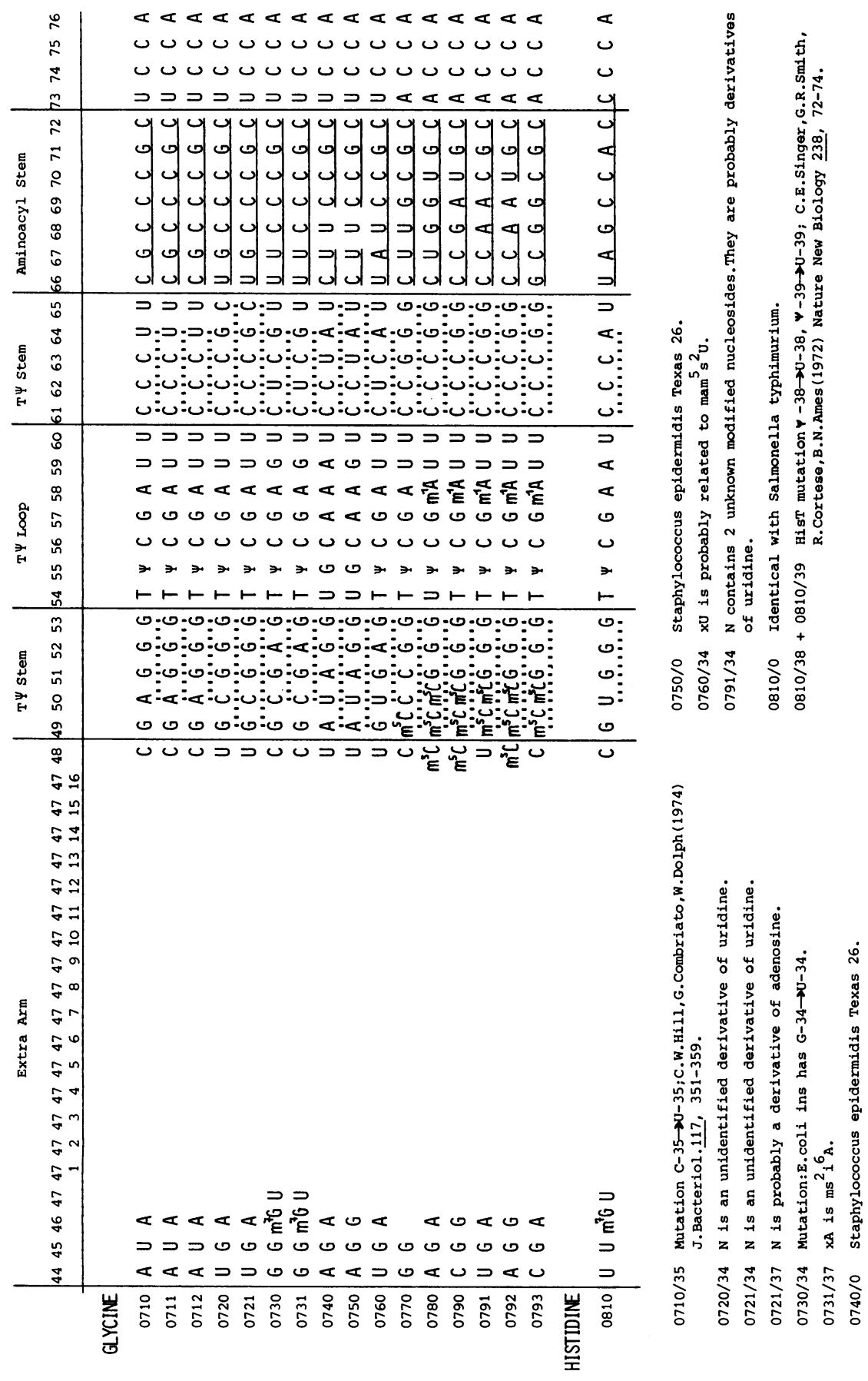




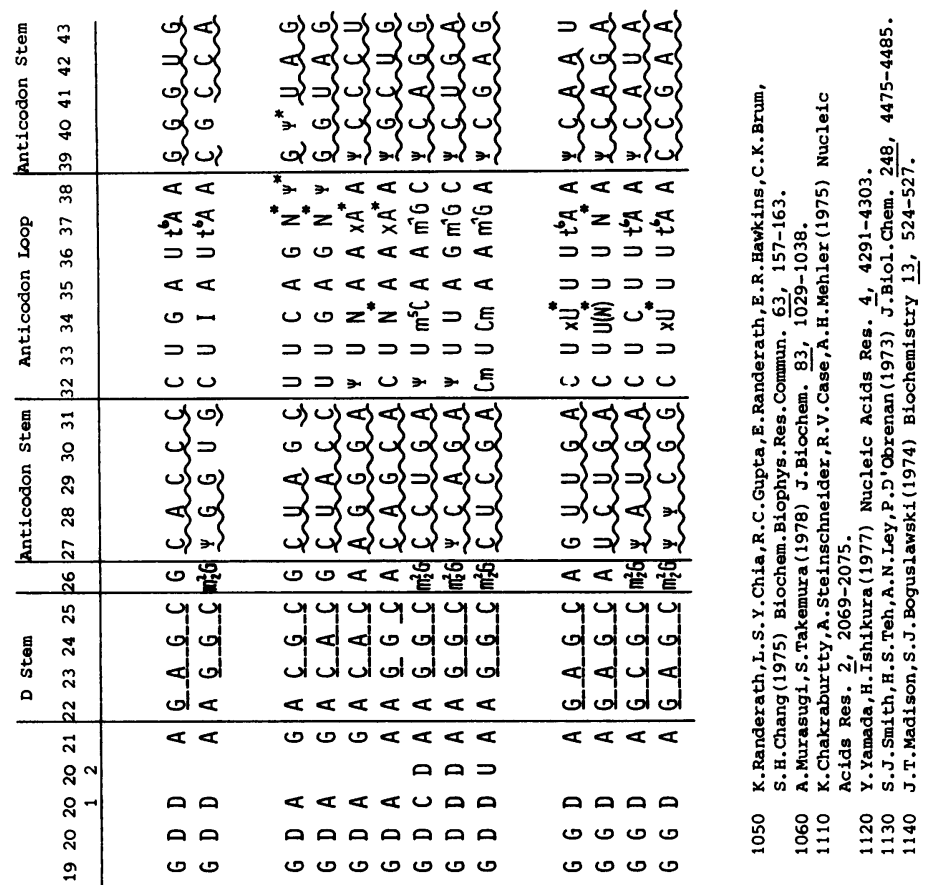

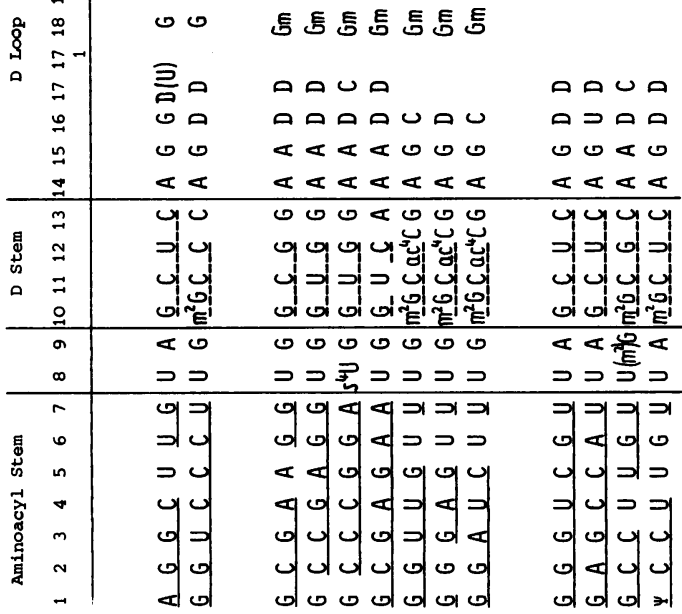

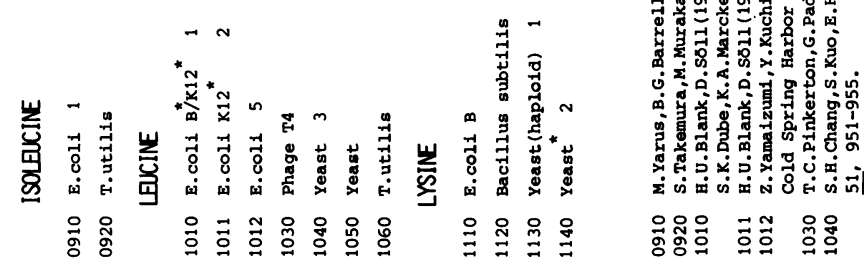



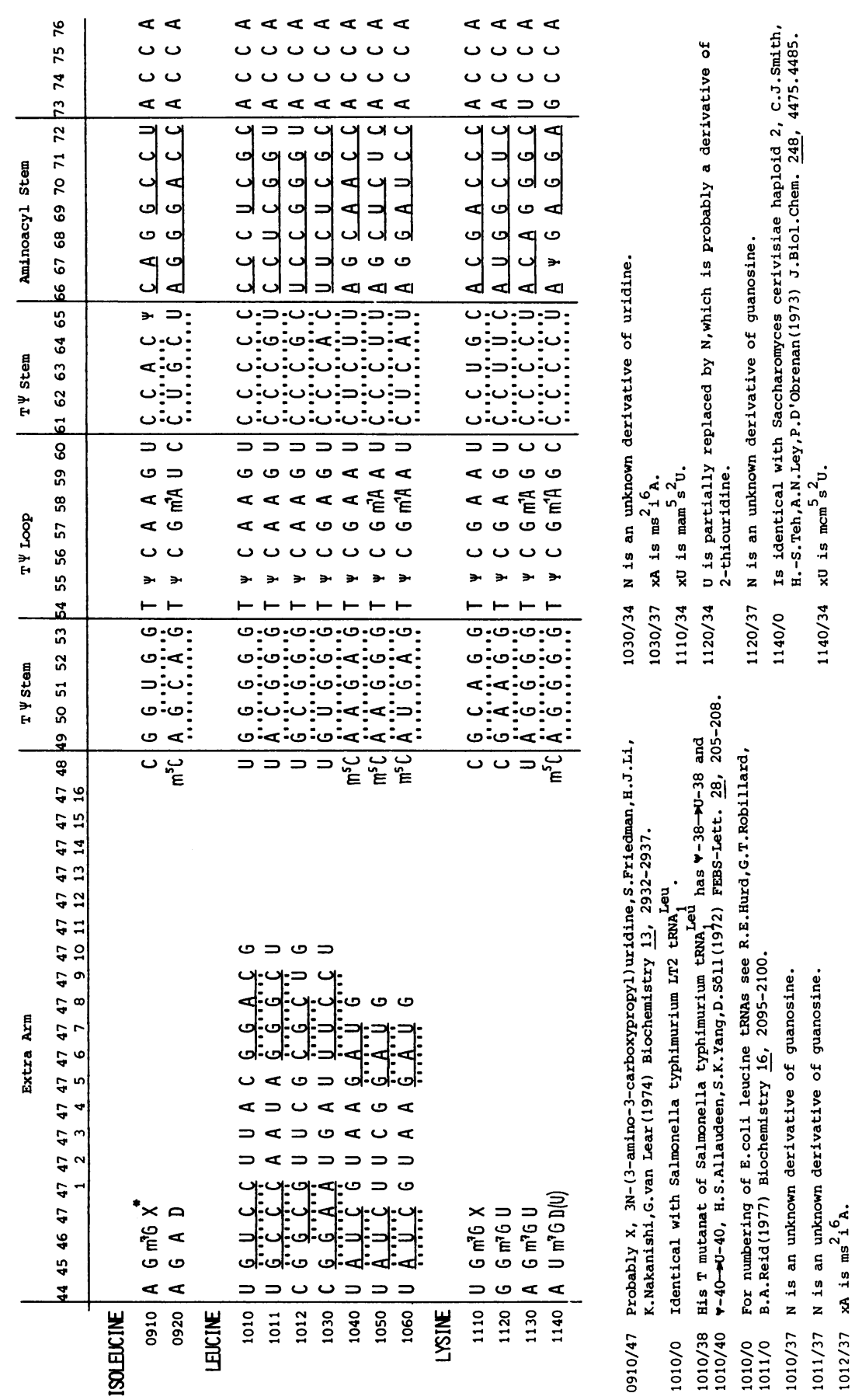


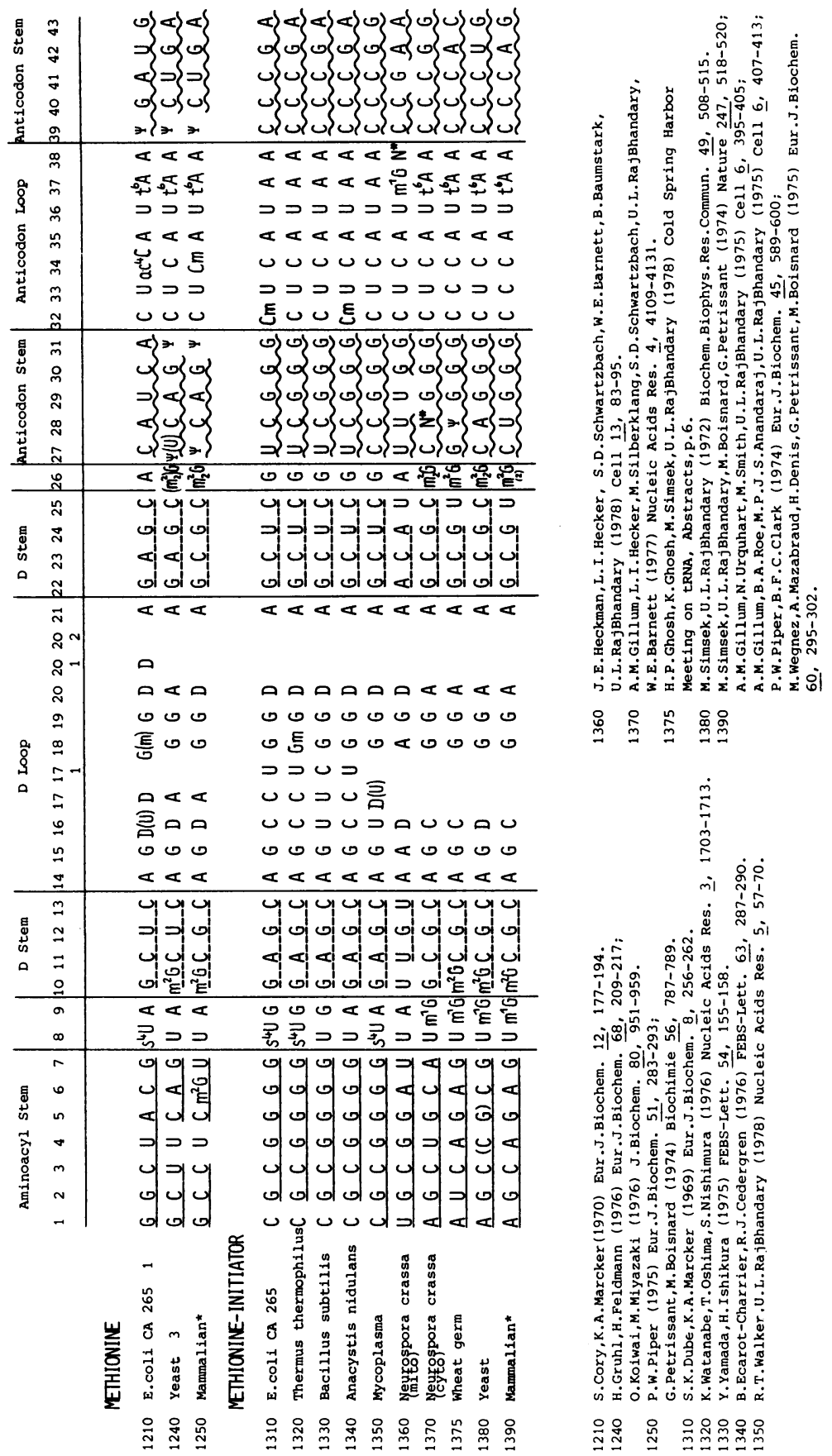



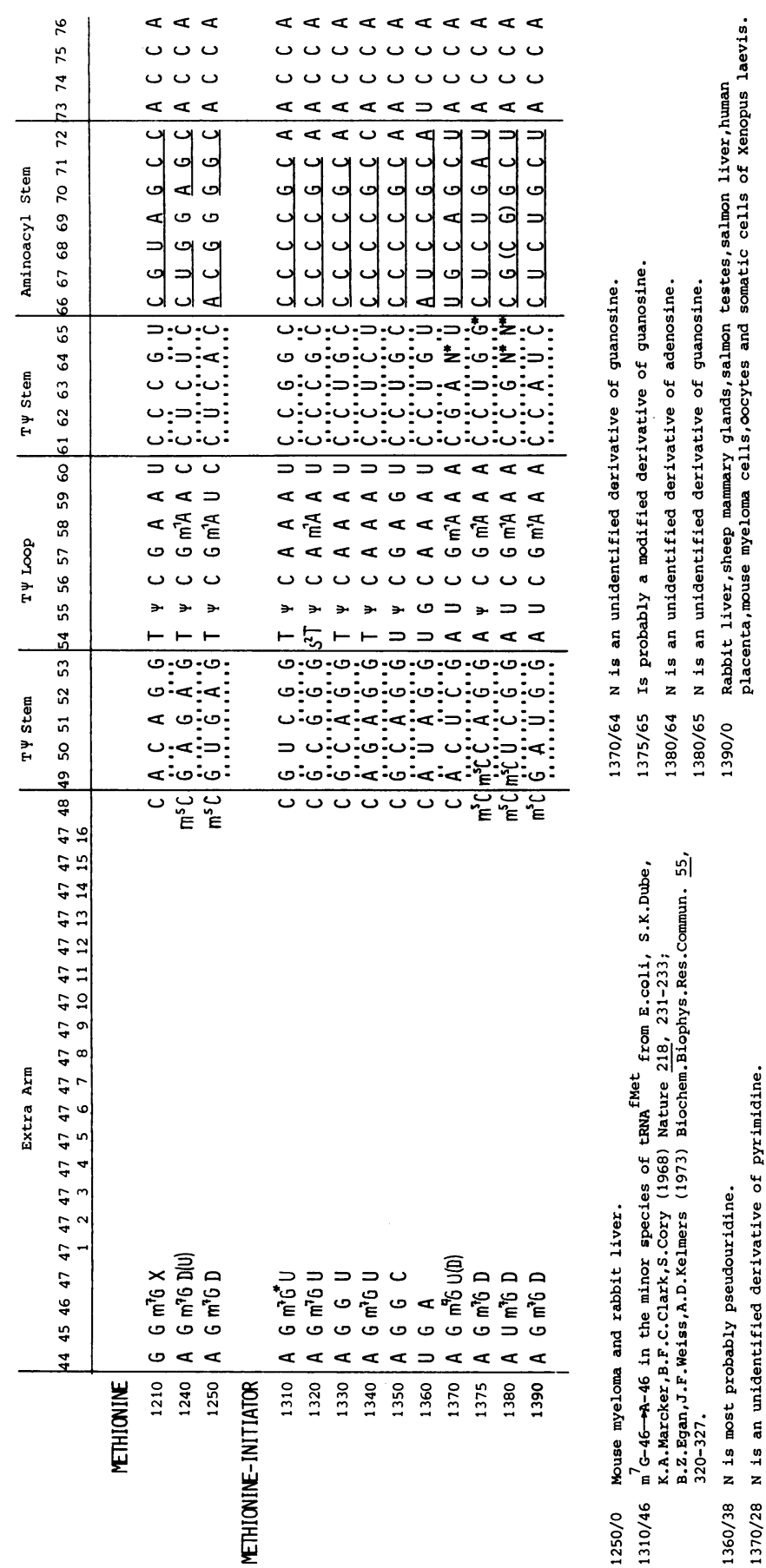

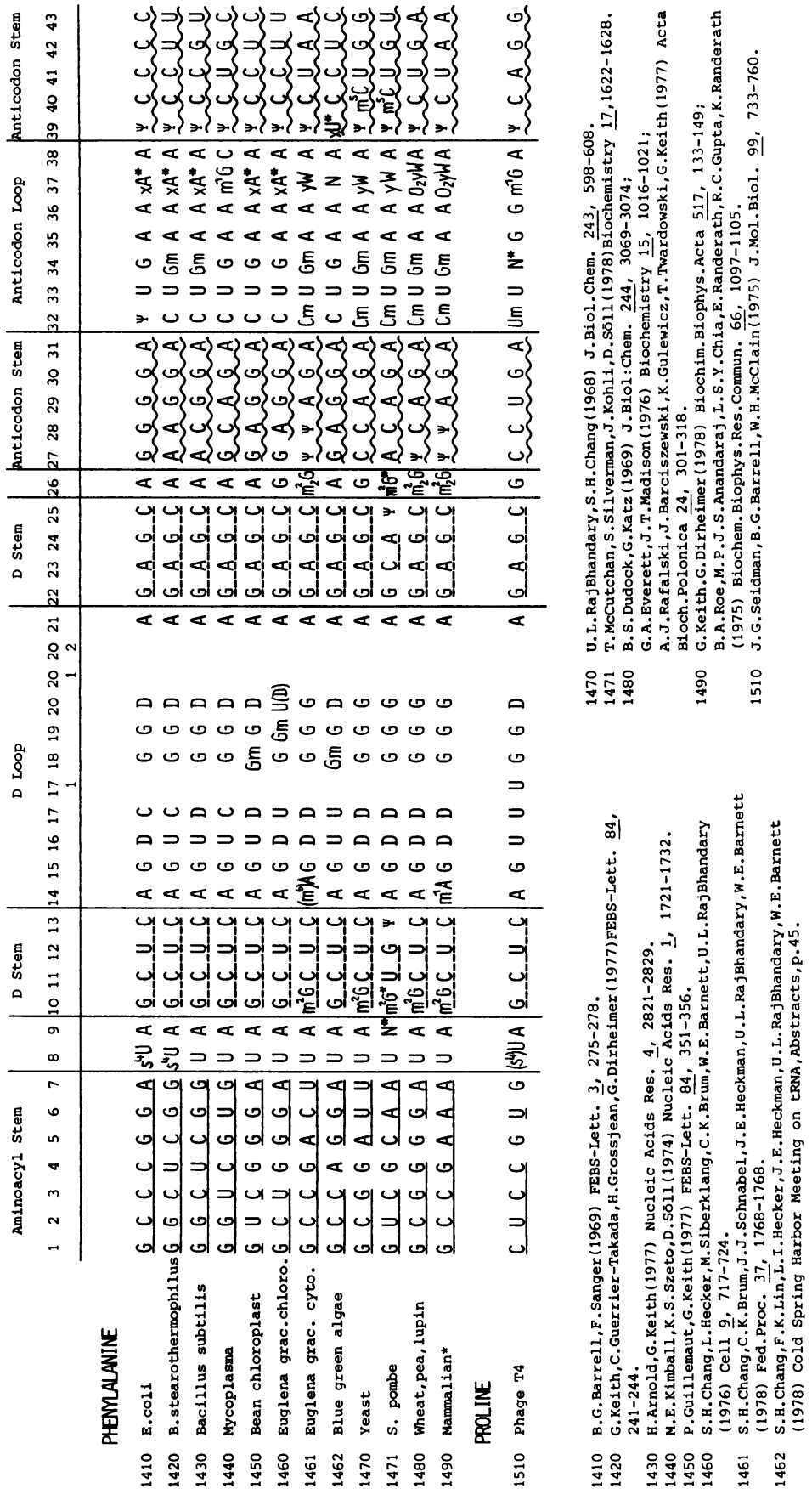


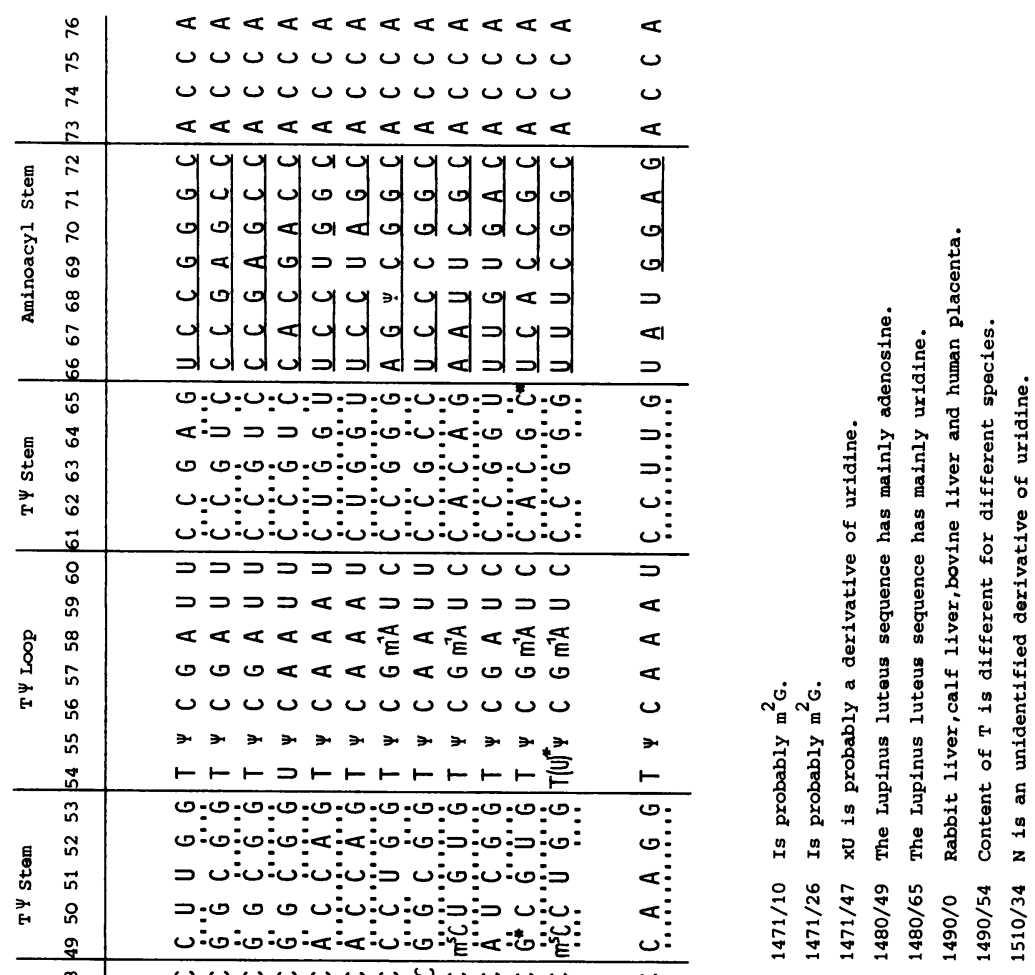

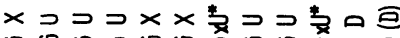

D心 0 D心

들

כコ כ כ

అ

ڤ

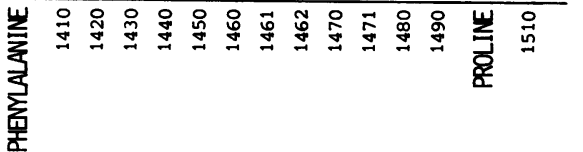

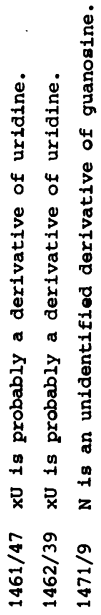




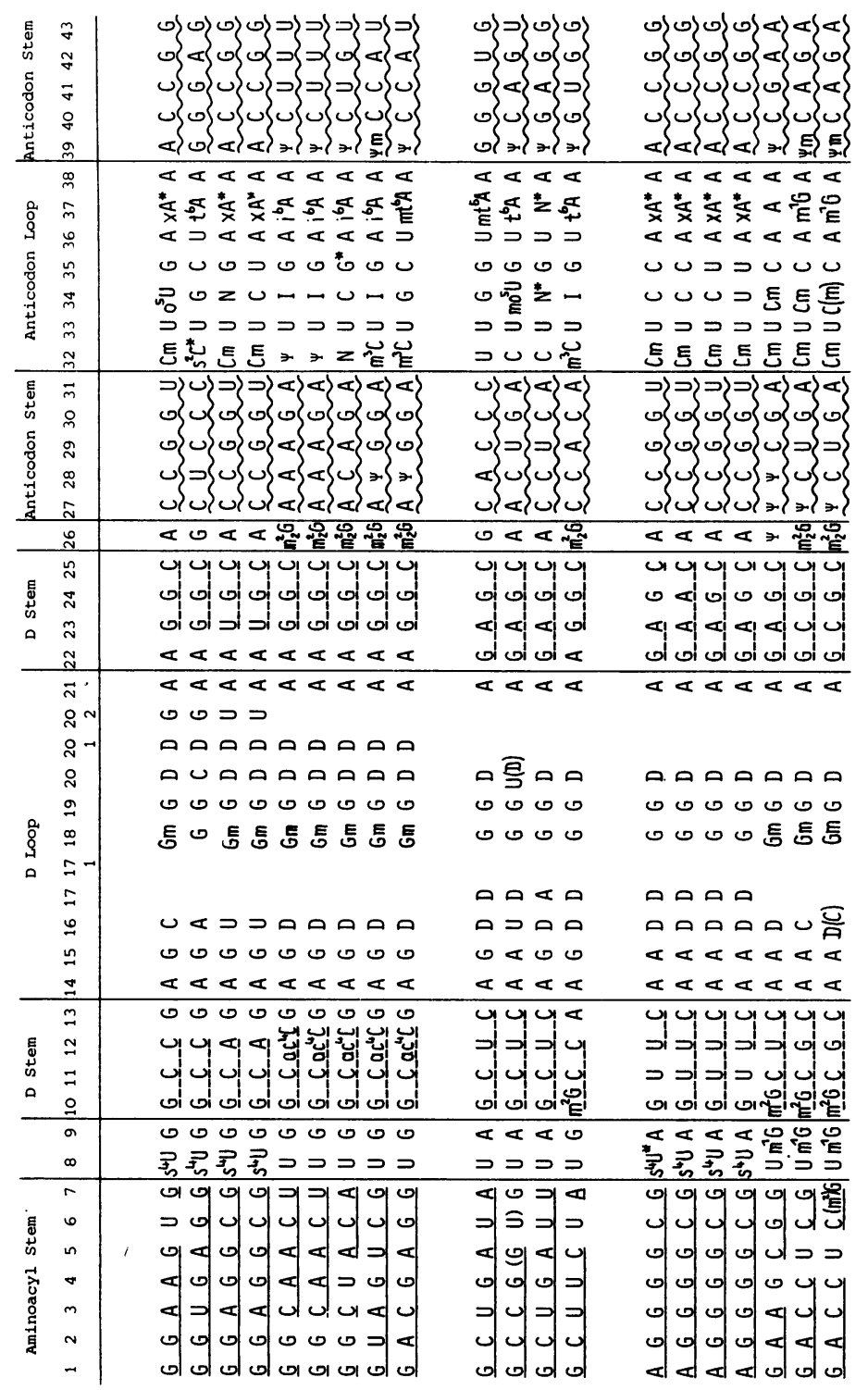

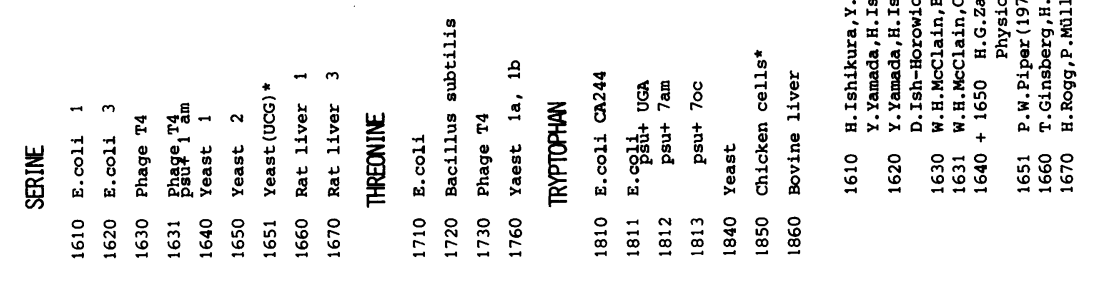




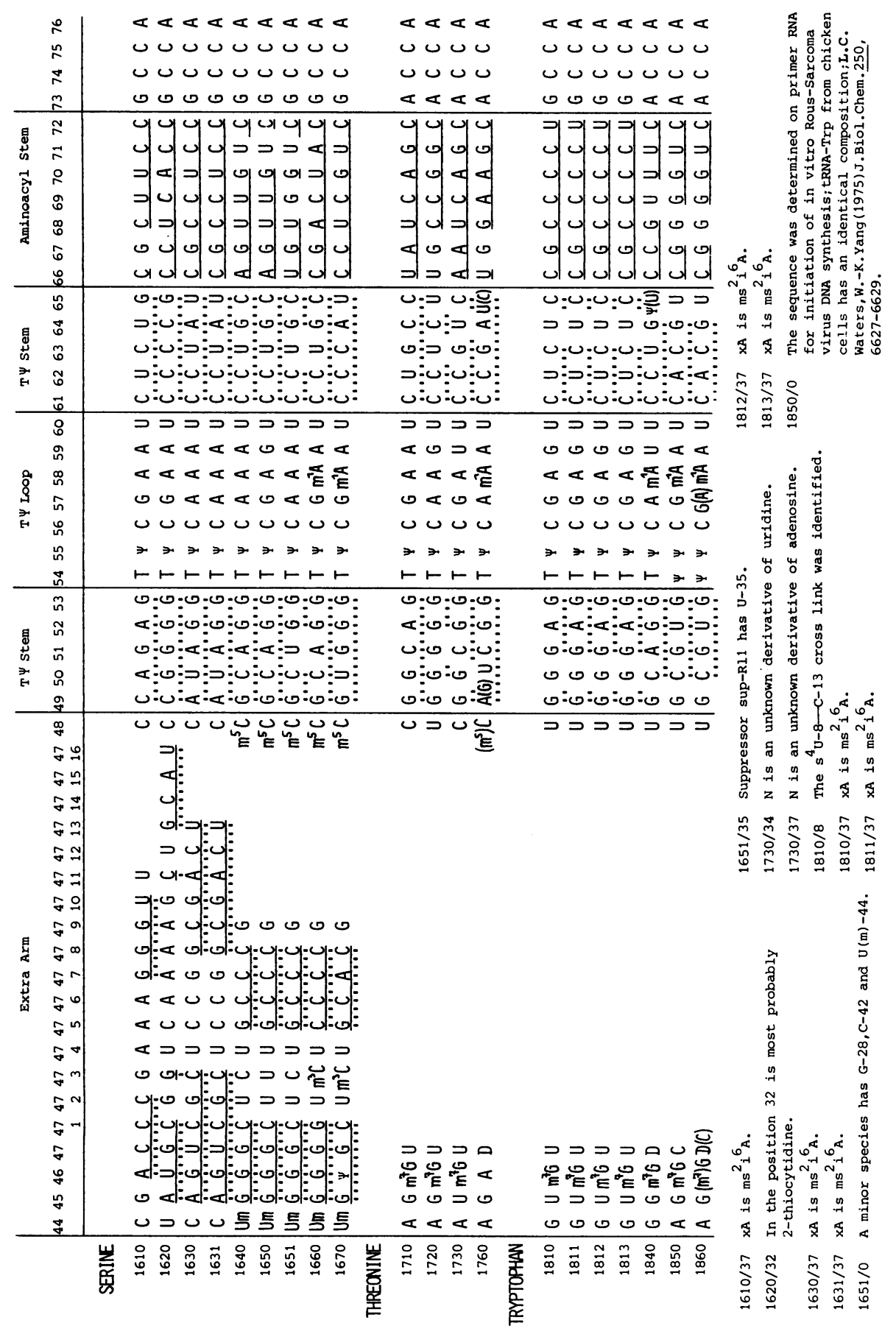




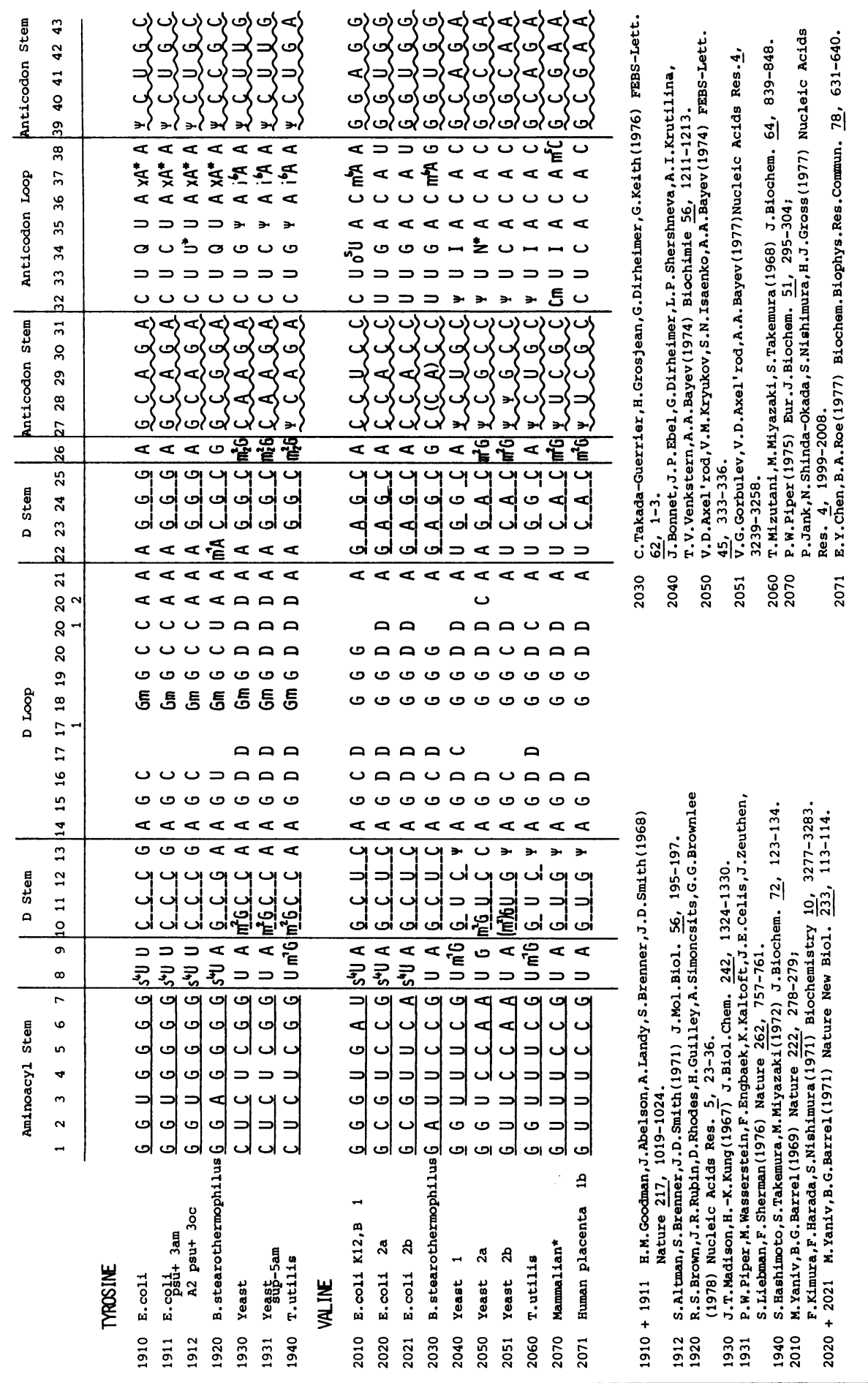




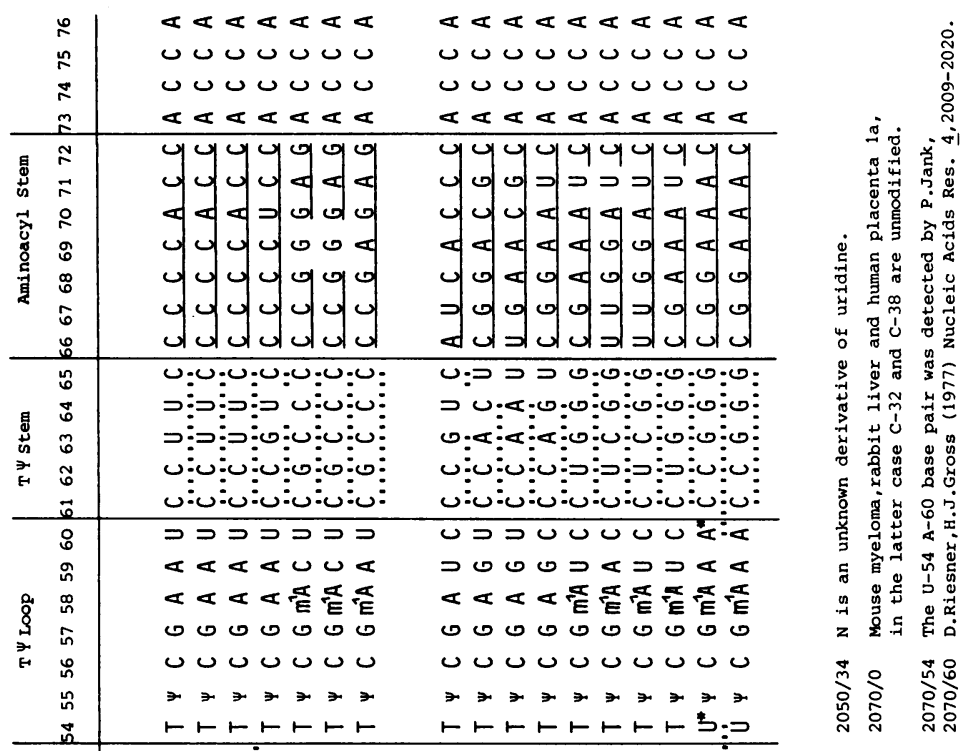

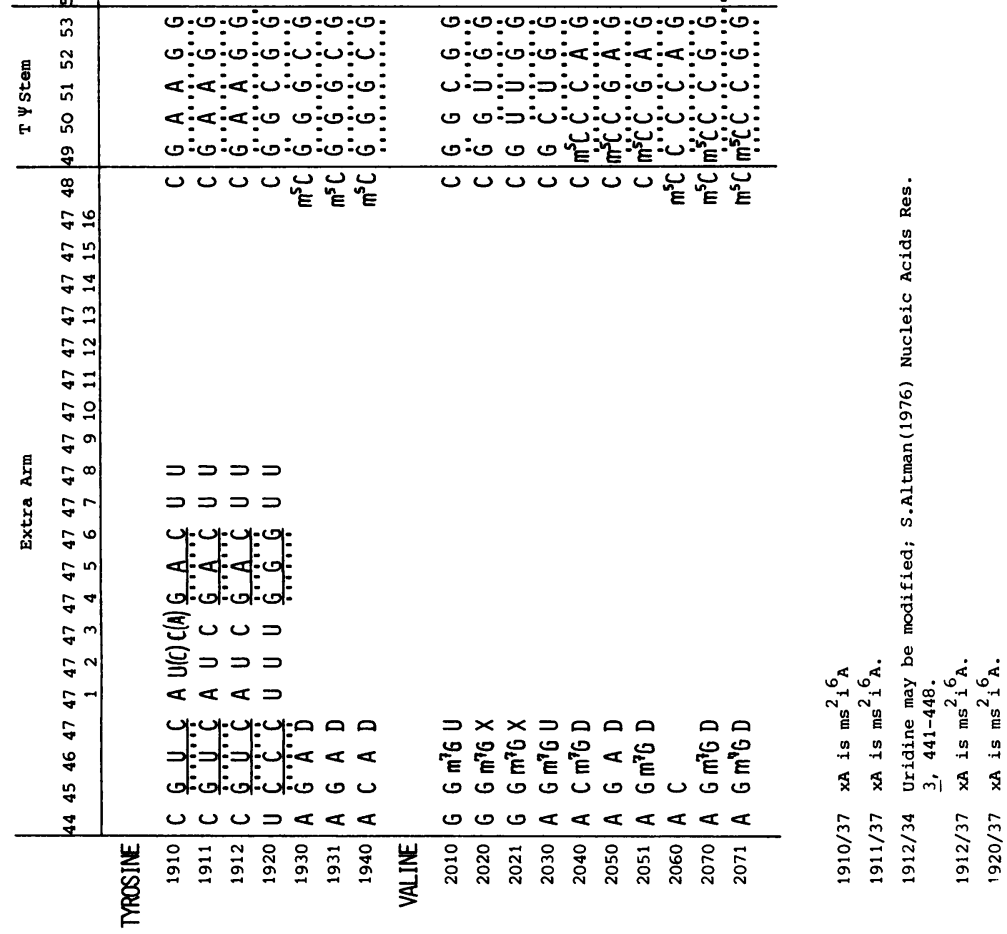

